\title{
UMA COLEÇÃO DE CERÂMICA LIGADA À HISTÓRIA DO XOKLENG
}

\author{
A CERAMIC SAMPLE CONNECTED WITH THE XOKLENG HISTORY \\ Jefferson Aldemir Nunes ${ }^{1}$, Pedro Ignacio Schmitz ${ }^{2}$
}

\section{RESUMO}

Estudo de uma coleção de cerâmica da fase Cantu, tradição Itararé, da bacia do rio Piquiri: análise técnica, contextualização cultural, comparação com estudos feitos em áreas do planalto meridional ocupadas no período colonial por etnia Xokleng e possível relação com a memória dos Xokleng atuais de Santa Catarina.

Palavras-chave: Fase Cantu; Tradição Itararé; Planalto meridional; Xokleng; Memória.

The study of a ceramic collection of the Cantu phase, Itarare tradition, of the Piquiri fluvial basin: technical analysis, cultural context, comparison with similar studies on the south Brazilian highlands settled in the colonial time by Xokleng Indians and a possible relation to the memory of the present Xokleng of Santa Catarina.

Keywords: Cantu phase; Itararé tradition; South Brazilian highlands; Xokleng; Memory.

\footnotetext{
${ }^{1}$ Graduando do curso de Licenciatura Plena em História, pela Universidade do Vale do Rio dos Sinos (UNISINOS).

${ }^{2}$ Doutor em História e Geografia, Livre Docente em Antropologia, Pesquisador Senior do CNPQ.
} 


\section{INTRODUÇÃo}

O trabalho tem como objeto o estudo de uma amostra de cerâmica da Fase Cantu, da Tradição cerâmica Itararé, recolhida em superfície, no município de Nova Cantu, doada pelo pároco da igreja local, P. Rui Körbes, ao Instituto Anchietano de Pesquisas/UNISINOS. O objetivo é seu estudo tecnológico, a comparação dos resultados com os da fase Cantu, publicados inicialmente por Chmyz \& Sauner (1971), depois por Chmyz (1976, 1977, 1978 e 1979) e ainda por Schmitz \& Rogge (2008). O estudo pode ajudar a entender a história da etnia Xokleng no planalto do Paraná e de Santa Catarina e a relação que essa história tem com as populações Xokleng da Mata Atlântica de Santa Catarina.

Nova Cantu se localiza na bacia do rio Cantu, afluente da margem direita do rio Piquiri, que desemboca no rio Paraná, pela margem esquerda, no Estado do Paraná. A localização geográfica do município é de aproximadamente $52^{\circ} 30^{\prime}$ de longitude $\mathrm{W}$ e $24^{\circ} 40^{\prime}$ de latitude $\mathrm{S}$, e a altitude entre 500 e $1000 \mathrm{~m}$. O ambiente geral era de campos com bosques de araucária e mata adensada ao longo dos cursos de água e em áreas de menor altitude, além de pequenos encraves de cerrado.

Figura 1. Localização da área donde vem a amostra estudada.

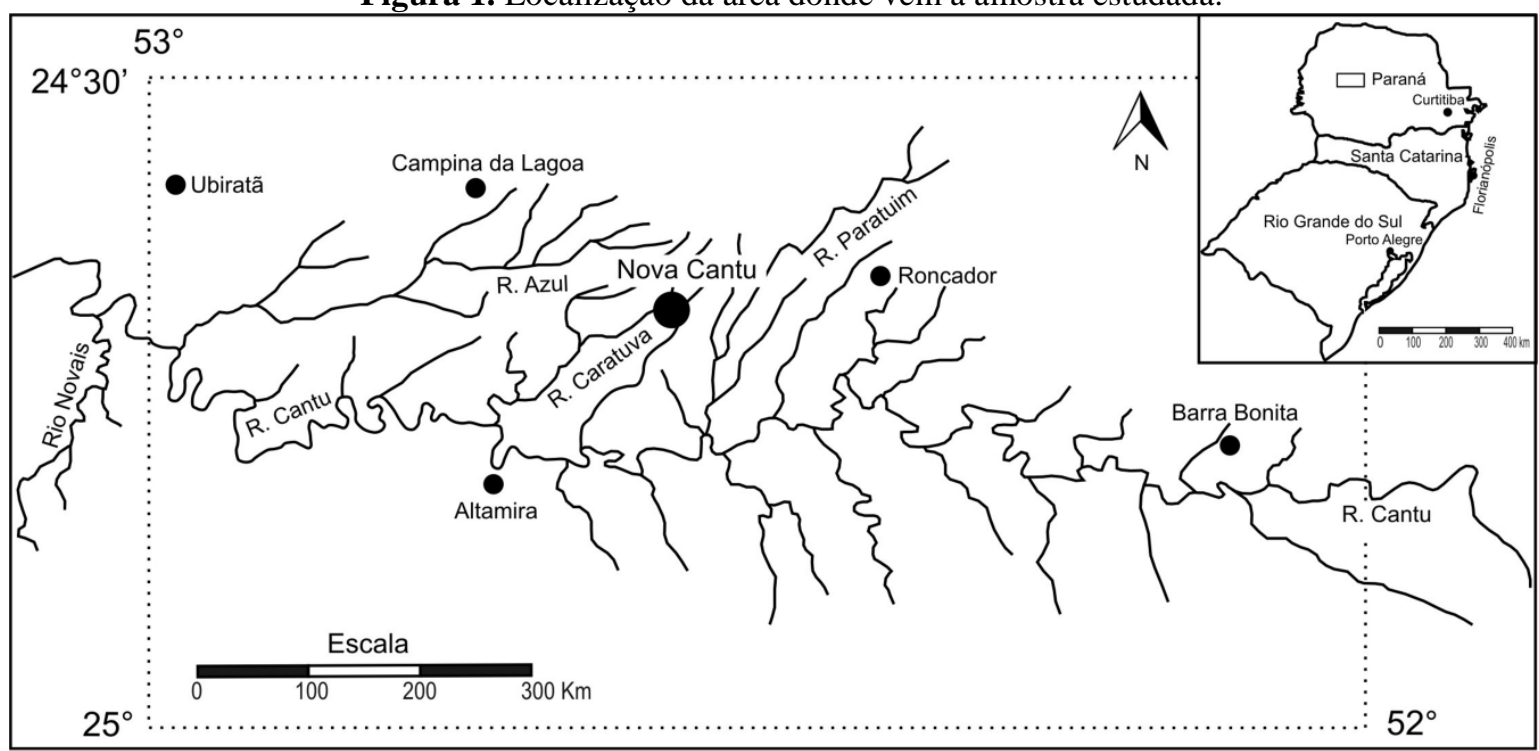

Adaptado de: Carta do Brasil ao milionésimo. IBGE. Rio de Janeiro: 1972. 
A amostra coletada compõe-se de 234 fragmentos de cerâmica em boas condições de conservação, dos quais 56 são bordas, 17 bases e 161 fragmentos de bojo. Os fragmentos foram separados em três grupos de acabamento superficial simples: um simples acinzentado, um simples avermelhado e um simples intermediário, além de um decorado plástico avermelhado.

Figura 2. Fragmentos representando os grupos pela coloração: a faixa de cima os avermelhados, a de baixo os acinzentados, a do meio os intermediários.

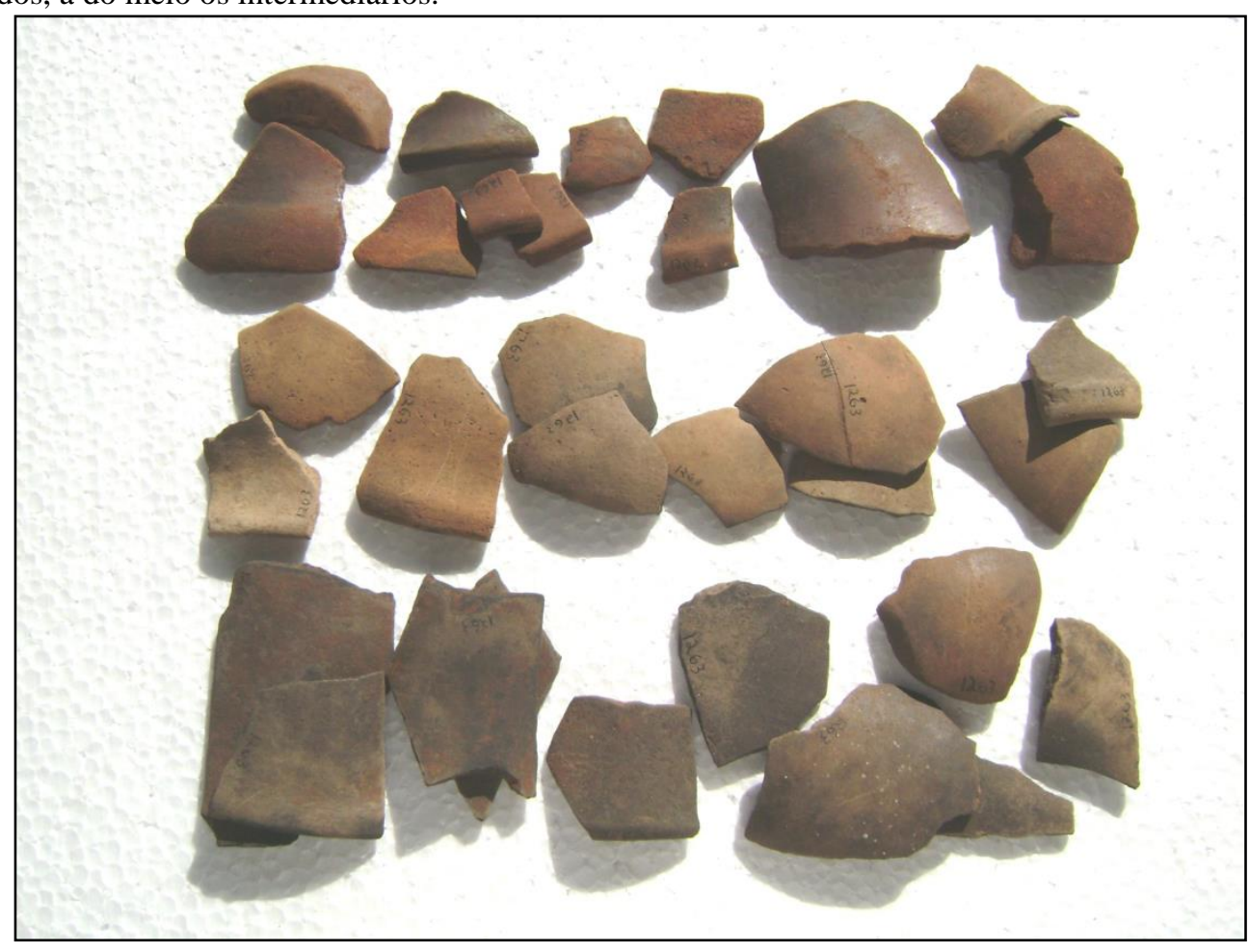

Figura 2. Fragmentos decorados avermelhados. 


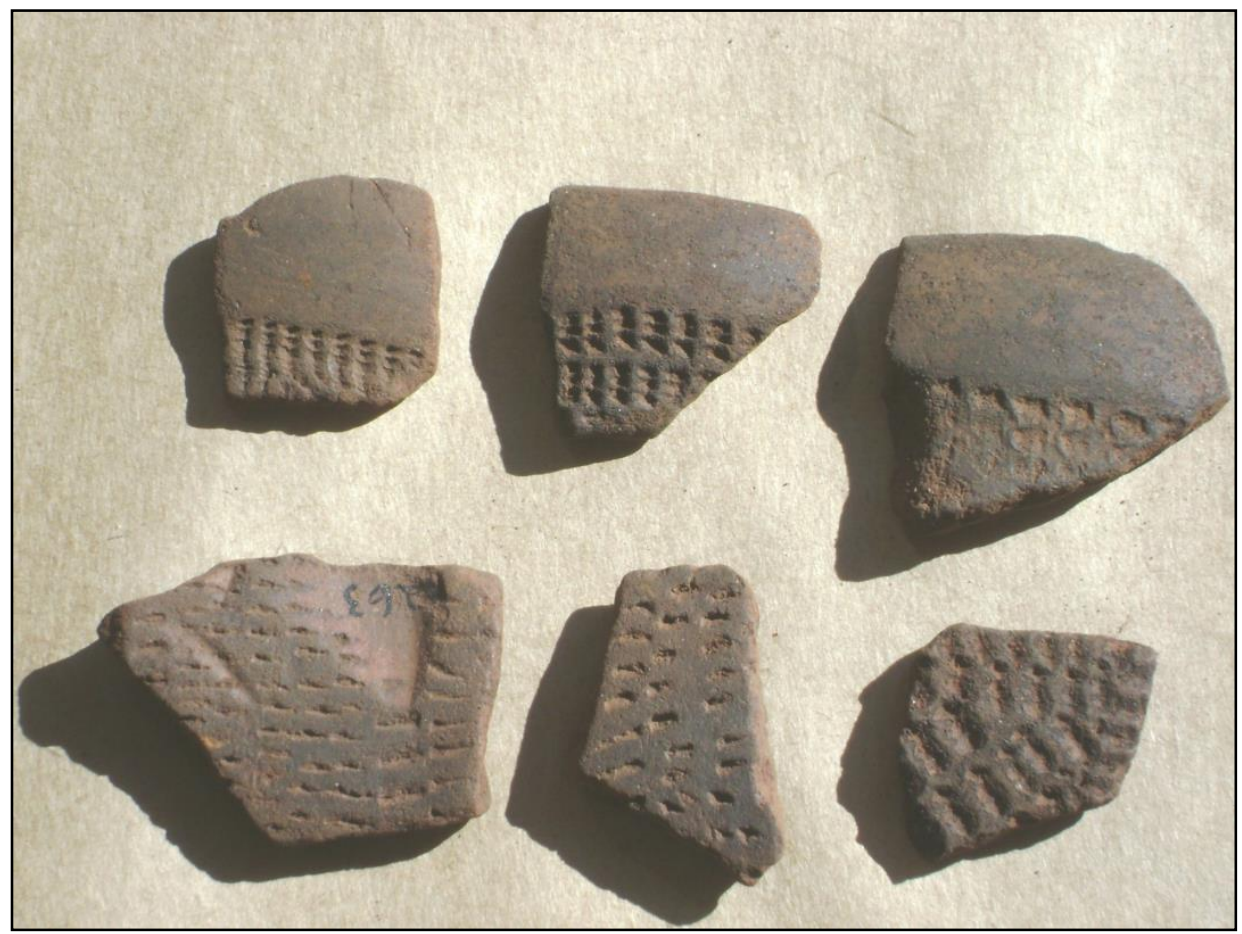

A tabela mostra a distribuição do material pelos grupos.

Tabela 1. Distribuição do material por grupos.

\begin{tabular}{c|c|c|c|c|c}
\hline Grupos & $\begin{array}{c}\text { Simples } \\
\text { Vermelho }\end{array}$ & $\begin{array}{c}\text { Simples } \\
\text { Acinzentado }\end{array}$ & $\begin{array}{c}\text { Simples } \\
\text { Intermédio }\end{array}$ & $\begin{array}{c}\text { Decorado } \\
\text { Plástico }\end{array}$ & Total \\
\hline Bordas & 13 & 20 & 18 & 05 & 56 \\
\hline Fragm. Bojo & 39 & 78 & 37 & 07 & 161 \\
\hline Bases & 04 & 06 & 07 & 00 & 17 \\
\hline Total & 56 & 104 & 62 & 12 & $\mathbf{2 3 4}$ \\
\hline
\end{tabular}

Foram encontrados ainda cinco fragmentos cerâmicos intrusivos, da tradição Guarani, e um fragmento de cerâmica moderna. Ainda uma pequena lasca secundária de riolito, com gume transversal apto para servir como faca.

\section{O ESTUDO DO MATERIAL}

Em seus trabalhos Chmyz (1976, 1977, 1978, 1979) criou numerosos tipos baseados no antiplástico e no acabamento de superfície. Diferentemente dessa prática, preferimos não criar tipos cerâmicos, visto que se percebe uma transição no uso do antiplástico, na cor da superfície e nas formas das vasilhas; os fragmentos decorados são poucos.

Como antiplástico aparecem dois tipos de material: cariapé e areia quartzosa com grânulos de hematita; em menor quantidade, outros elementos. O cariapé se apresenta sob a forma de pequenos filamentos esbranquiçados, ora inteiros ora quebrados, presentes na pasta 
com maior ou menor densidade. A areia quartzosa, com presença de grãos arredondados de hematita, apresenta-se muito fina a fina. Com isolados fragmentos maiores de quartzo.

A proporção, na pasta, dos dois tipos de antiplástico manifesta-se na textura, no acabamento da parede, na sua espessura e na cor das vasilhas. Nos fragmentos com predominância de cariapé temos paredes finas, escuras, com textura compacta, superfícies com sensação de suavidade ao tato. Nas peças com antiplástico de areia e grãos de hematita temos paredes mais grossas, avermelhadas, textura compacta, sensação de aspereza ao tato e frequência de brunido preto tanto na face externa como na interna. Nos fragmentos com mistura de cariapé e areia temos vasilhas com características intermédias.

A quase totalidade dos fragmentos provém de vasilhas apenas alisadas. O alisamento é bom a muito bom, raramente aparecendo estrias de alisamento. Os limites entre os segmentos que formam as paredes são claramente definidos: entre o lábio e a face interna, entre o lábio e a face externa, entre a parede externa e a base. As vasilhas com decoração plástica não se distinguem das vasilhas alisadas na confecção, no antiplástico e na forma.

A cerâmica não apresenta indícios de que tenha sido produzida por roletes; mas também não dá sinais de outro tipo de construção: as fraturas são irregulares e a pasta é uniforme e consistente.

O cozimento é bom, produzindo vasilhas resistentes, apesar da pequena espessura das paredes. Se ele é oxidante ou redutor só um trabalho experimental poderá dizer; a cor sozinha não o define porque provavelmente depende dos temperos que contém.

Nas paredes construídas, a espessura do núcleo costuma ser bastante maior que as correspondentes superfícies, tanto a interna como a externa. Nos vasilhames com predominância de cariapé este núcleo costuma ser preto ou cinza bem escuro; naqueles em que predomina a areia quartzosa com grânulos de hematita ele pode ser proporcionalmente mais avermelhado. A face interna e a externa se apresentam em matizes de cinza quando o antiplástico é cariapé, em matizes de vermelho quando o antiplástico é areia quartzosa com hematita.

A dureza é 3, na escala de Mohs.

Da cerâmica encontrada, foram desenhadas 50 bordas e 12 bases, que possibilitaram reconstituir as formas dos vasilhames.

As vasilhas com predomínio de cariapé costumam ter bordas infletidas, com pequeno reforço externo formando lábio biselado, abertura da boca entre quatro e $16 \mathrm{~cm}$, altura maior 
que a abertura da boca, bases arredondadas, planas ou côncavas, paredes variando entre dois e dez milímetros, com predominância de três a cinco milímetros; a cor no fator 2,5YR vai de 4/1 (Dark Gray) a N 2,5/1 (Black). Cores conforme Munsell Soil Color Charts, 1975.

As vasilhas com predomínio de areia quartzosa e grânulos de hematita apresentam formas de bordas contínuas, às vezes com reforço mais alargado e lábio mais arredondado, abertura da boca entre oito e $12 \mathrm{~cm}$, altura semelhante, às vezes inferior à da abertura da boca, bases arredondadas e um pouco reforçadas, paredes variando entre dois e $11 \mathrm{~mm}$, com predomínio de quatro a cinco mm, a cor no fator 10YR 3/6 (Dark Red).

As vasilhas com antiplástico cariapé e areia quartzosa com grânulos de hematita produzem também formas com características intermédias e cor no fator 2,5YR de 5/4 (Reddish Brown) e 6/4 (Light Reddish Brown).

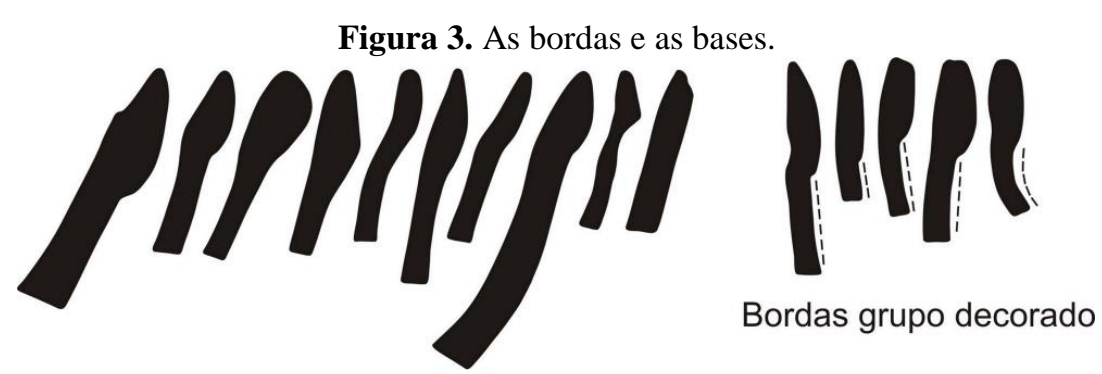

Bordas grupo vermelho

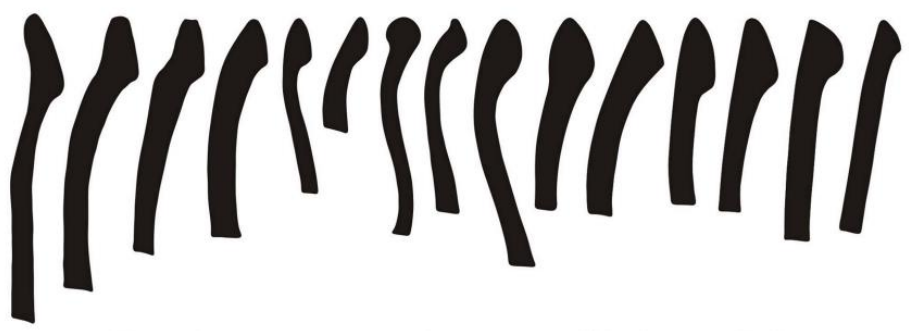

Bordas grupo cinzento / intermédio

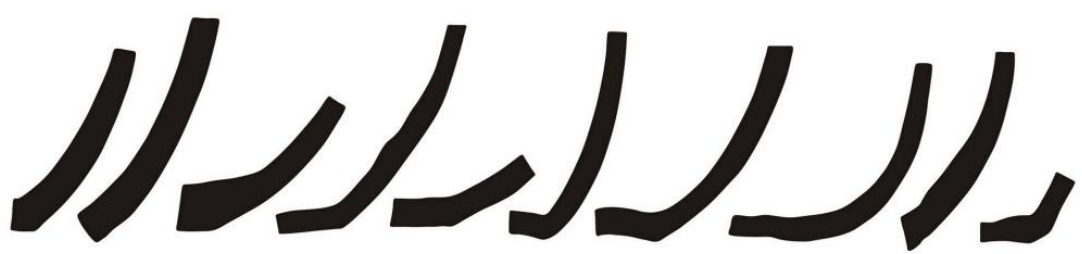

Bases

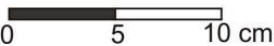


As vasilhas decoradas seguem, predominantemente, o padrão geral vermelho, mas também as formas do padrão cinza. A espessura da parede varia de três a seis $\mathrm{mm}$, com predominância de quatro a cinco mm, a abertura da boca, de oito a $14 \mathrm{~cm}$. A decoração é regular e bem feita, na face externa; inicia na parte superior da borda, cobre parte do corpo e acompanha as variações que Chmyz, em seus diversos trabalhos, classificou como carimbado.

Figura 4. Modelos de formas dos grupos, separados por coloração.

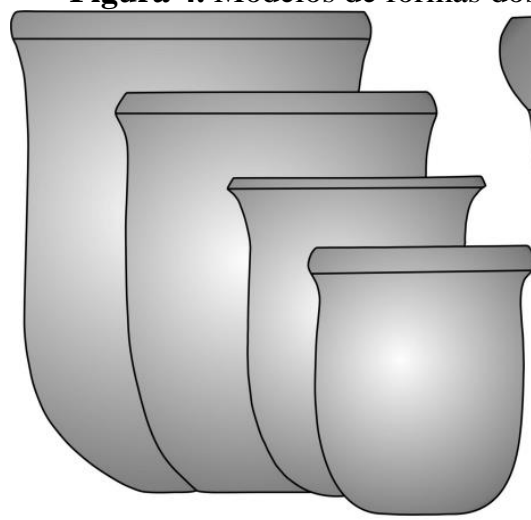

Formas grupo cinzento

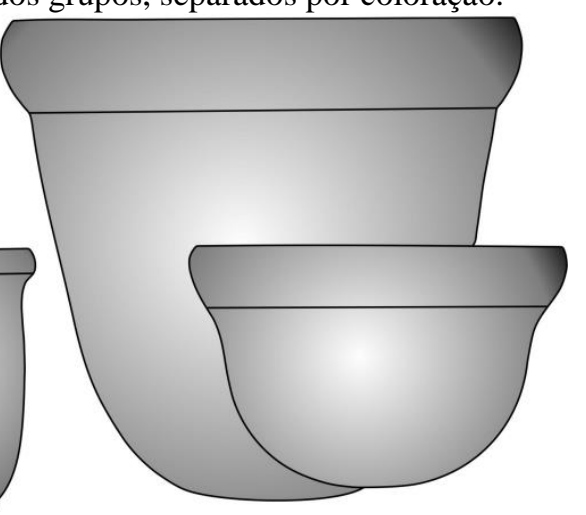

Formas grupo vermelho

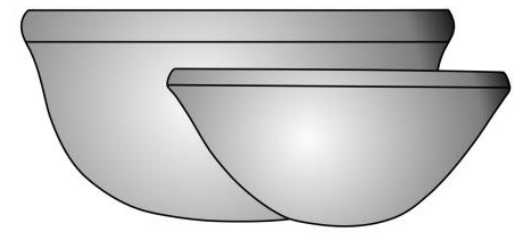

Formas grupo vermelho / intermédio

\section{DISCUSSÃO}

Na memória dos índios Xokleng, que em tempos coloniais e modernos viviam como caçadores e coletores na Mata Atlântica da encosta leste do Planalto Meridional, consta que, anteriormente, eles tinham vivido em terras altas como cultivadores estáveis. Os antropólogos especulam sobre como e quando eles teriam sido expulsos e teriam adotado o novo modo de vida (HENRY, 1941; SANTOS, 1973; LAVINA, 1994). Os linguistas Rivet e Loukokta (apud 
Chmyz; Sauner, 1971), assim como o Mapa Etnográfico de Nimuendaju (1981), ainda colocam, no século XIX, falantes Xokleng no interior do Paraná sobre o rio Piquiri e o rio Iguaçu.

Este é um convite para que os arqueólogos, em busca da construção de uma história para o Jê Meridional, pensem na ligação das evidências arqueológicas com os dados linguísticos do mesmo território, especialmente quando a cronologia da evidência arqueológica fica muito próxima da constatação linguística e etnográfica. Apresentaremos duas amostras arqueológicas que podem ser úteis para a construção desta história.

O planalto meridional era povoado em tempos recentes por índios conhecidos como Kaingang e como Xokleng, da família linguística Jê. Eles estão muito próximos, linguística e culturalmente, mas existem elementos que permitem distingui-los. Esta distinção é importante para podermos falar de uma história Xokleng separada de uma história Kaingang. Apresentamos algumas dessas diferenças.

A língua Xokleng, segundo a linguista Wiesemann (1978), é mais antiga que a Kaingang. O Xokleng crema seus mortos (LAVINA, 1994), o Kaingang realiza sepultamento primário dos corpos (MABILDE, 1897). A cerâmica aparece tardiamente no território atribuído ao Xokleng e, quando aparece, é da pouco decorada tradição Itararé (SCHMITZ et al., 2013a); no território atribuído ao Kaingang a cerâmica aparece com os primeiros assentamentos e é da decorada tradição Taquara (SCHMITZ, 1988; SCHMITZ; ROGGE, 2013). Ainda pode entrar na especulação a distribuição territorial dos grupos no período colonial, o Kaingang na parte meridional e o Xokleng na setentrional do território.

Se usarmos simultaneamente estes critérios podemos tentar uma identidade étnica para a população da fase Cantu, estudada na bacia do rio Piquiri por Chmyz \& Sauner (1971), atribuindo os achados aos antepassados de índios da etnia Xokleng.

A imagem que, então, se nos apresenta é de uma população adaptada ao planalto, onde constrói casas subterrâneas e aldeias a céu aberto, em área dominada por floresta subtropical mista com abundantes pinheiros, tendo na proximidade a floresta latifoliada subtropical e encraves de cerrado, crescendo sobre relevo bem drenado, com solos bons para cultivos, clima temperado e chuvas distribuídas por todo o ano. A área, de tensão ecológica entre diversas formas de vegetação, se prestaria vantajosamente para manejo florestal, além de algum cultivo de plantas tropicais (CORTELETTI, 2012). O cultivo também é indicado pela associação de pessoas da fase Cantu com populações agrícolas da tradição cerâmica Aratu, em Apucarana 
(SCHMITZ; ROGGE, 2008) e com populações agrícolas da tradição cerâmica Guarani em diversos lugares próximos (CHMYZ; SAUNER, 1971).

A exploração de encraves de cerrado na proximidade manifesta-se na fabricação de seus elegantes potes, usando a cinza de uma árvore deste ambiente, o cariapé, já anotado por Schmitz \& Rogge (2008) no sítio multicomponencial de Apucarana.

A presença, no meio das casas, de um alto aterro-plataforma, com 13 m de diâmetro, construído, em sucessivas etapas, desde o século XI até o século XV de nossa era, é indicador de continuidade na ocupação da área. Espessas camadas de cinzas provenientes de cremação humana no aterro testemunha o típico tratamento dos mortos do grupo Xokleng. Grupos desta etnia ainda habitavam a região no período colonial (NIMUENDAJU, 1981).

O conjunto dessas informações baseia nossa hipótese de continuidade local entre a história construída pelos arqueólogos e a contada pelos cronistas, linguistas e etnógrafos como sendo Xokleng. Para formar o contexto regional juntamos mais alguns dados.

No meio da área, da qual provém a amostra, passava um antigo caminho indígena (o Piabiru), pelo qual se deslocavam inicialmente indígenas, depois também colonizadores europeus. No começo do século XVII sobre o rio Paraná e seus afluentes foram instaladas pequenas cidades castelhanas (Ciudad Real e Vila Rica do Espírito Santo) e 13 reduções jesuíticas que incorporaram os índios guaranis, mas também populações do grupo linguístico Jê da periferia destas. Montoya teria fundado com eles, em 1628, a redução de Conceição dos Gualachos, ou Xokrê, nas margens do rio Piquiri (BASILE BECKER, 1992). Na sequência houve na área intensa movimentação bandeirante caçando índios independentes e missionados para as fazendas paulistas. Mesmo assim sobreviveram na região populações de língua Xokleng (NIMUENDAJU, 1981).

O conjunto desses elementos, embora fragmentários, pode ser usado como material para a construção de uma história de longa duração do grupo implantado sobre o rio Piquiri. Se ela está diretamente ligada com o grupo Xokleng da Mata Atlântica ou com algum grupo desaparecido, os dados ainda são incapazes de informar.

A fase Cantu, das margens do rio Piquiri, no Paraná, não está sozinha no fornecimento de dados para a construção dessa longa história indígena. Muito semelhante a ela, mais rica, cronologicamente mais longa, é a informação para uma área no município catarinense de São José do Cerrito, nos campos de Lages (SCHMITZ et al., 2013; SCHMITZ, 2014; SCHMITZ et al., 2016). 
Ali foi estudado um denso aglomerado de 19 sítios com mais de 50 casas subterrâneas, quatro aterros-plataforma semelhantes aos da fase Cantu e um 'danceiro' composto por quatro 'estruturas anelares'. As casas, em média, são maiores que as do rio Piquiri, tendo uma delas 19,50 m de diâmetro e seis metros de profundidade, outra $14 \mathrm{~m}$, várias de $12 \mathrm{~m}$ de diâmetro. Também os aterros-plataforma: um tem $30 \mathrm{~m}$ de diâmetro e 2,20 m de altura; os outros três têm aproximadamente $20 \mathrm{~m}$ de diâmetro e um metro de altura. Além da forma geral das estruturas, são parecidos até os pormenores da construção dos aterros-plataforma. Neles se fizeram cremações e existem camadas de cinza cobertas por aquilo que os autores paranaenses chamam 'escória de ferro', material que em São José do Cerrito identificamos como a rocha 'itacuru', rica em minério de ferro; se fortemente aquecida, como numa cremação, ela se transforma em hematita intensamente vermelha.

Cada um dos aterros-plataforma, bem como o conjunto de estruturas anelares, está associado a uma casa muito grande ou a um conjunto de casas, como demonstram as correspondentes datas de C14. A cerâmica presente nessas construções é da tradição Itararé, como a do Piquiri, e pouco se distingue daquela.

A cronologia do conjunto da Boa Parada vai de 990 a 1630 de nossa era, mostrando a mesma continuidade e densidade na ocupação do espaço.

No período final indicado por essas datas os portugueses já tinham começado a se instalar na planície litorânea de Santa Catarina e, mais longe, no Paraná e no Rio Grande do Sul, os jesuítas tinham iniciado as missões com os guaranis das planícies fluviais. Estas iniciativas ainda interferiam pouco no planalto entre os rios Pelotas e Canoas, formadores do rio Uruguai, onde se localizam os sítios estudados.

Mas já em 1629 paulistas criaram a primeira estância nos Campos de Lages, segundo mostra grande pintura mural na estação rodoviária de Lages. São José do Cerrito dista escassos $40 \mathrm{~km}$ desta cidade. Na década de 1630 passaram por ali sucessivas bandeiras com muitos paulistas e milhares de índios auxiliares para apresar índios das missões que os jesuítas estavam fundando no Rio Grande do Sul, e por ali voltavam com muitos milhares de prisioneiros. Mais algumas décadas e foi aberto o caminho das tropas, que durante todo o século XVIII levava cavalos e gado de Montevideo e de Viamão para o mercado de Sorocaba, em São Paulo (SCHMITZ; NOVASCO, 2013).

Os ocupantes nativos reagiam a esta invasão e por isso foi construído nos Campos de Lages, principal estação de parada neste caminho, um forte para defender os mercadores e 
viajantes e manter longe os índios. Do forte nasceu em 1771 a vila, que hoje é a cidade de Lages (Enciclopédia dos Municípios Brasileiros IBGE, 1959).

No mapa etnográfico de Kurt Nimuendaju (1981) não se registra nenhuma etnia específica para os campos e pinheirais entre os dois rios mencionados, onde ficam os Campos de Lages, aparecendo sem dono o espaço em que a arqueologia mostra uma população indígena antiga que se tornara densa, estável e sedentária entre o século X e XVII de nossa era.

Mas na primeira metade do século XIX Mabilde (1897 e 1899) registra no planalto ferozes combates entre os Xokleng e os Kaingang; os primeiros, segundo Mabilde, então dominavam a encosta e, na época da maturação do pinhão, subiam ao planalto, cujo domínio já era pretendido pelos Kaingang. Desses encontros fala também Cunha (2012). Antigos moradores do lugar também recordavam o famoso Martim Bugreiro, que até ali teria chegado para caçar índios Xokleng, cobrando por pares de orelhas (MACHADO, 2004).

A pergunta ainda sem resposta é como se despovoou esta área, a mais rica em sítios do grupo Jê Meridional do Sul do Brasil até o século XVII, e para onde foram seus moradores. A hipótese é de que os últimos remanescentes se teriam refugiado na Mata Atlântica da encosta. Teriam deixado um desenvolvido manejo da Mata Mista com Araucária junto com alguns cultivos tropicais a partir de assentamentos sedentários e se transformado em caçadores e coletores móveis na Mata Atlântica da encosta.

São fortes os indícios de que as duas áreas examinadas são de populações Xokleng, que dominavam o planalto antes da penetração do colonizador europeu. A história posterior dessas populações, no confronto com exploradores e colonizadores, que desembocou na formação do Xokleng de hoje, só pode ser contada a partir de documentos escritos, trabalho reservado aos historiadores.

\section{CONSIDERAÇÃO FINAL}

Cada amostra cerâmica, como a pequena coleção superficial de Nova Cantu, junto ao rio Piquiri, no Paraná, doada ao Instituto Anchietano de Pesquisas pelo pároco da igreja local, pode servir de provocação para voltar à história dos Xokleng e tentar uma explicação para o grupo da Mata Atlântica do vale do rio Itajaí, no norte do Estado de Santa Catarina, que foi sacrificado quando a colônia alemã de Blumenau foi criada no centro de seu refúgio.

\section{REFERÊNCIAS}


BASILE BECKER, Í. I. O Kaingang histórico e seus antepassados. Arqueologia do Rio Grande do Sul, Brasil. Documentos 2, São Leopoldo, Instituto Anchietano de Pesquisas, p. 131-139, 1992.

CHMYZ, I. et al. Primeiro relatório das pesquisas realizadas na área de Itaipu (1975-1976). Curitiba: Convênio Itaipu-IPHAN, 1976.

CHMYZ, I. et al. Segundo relatório das pesquisas realizadas na área de Itaipu (1976-1977). Curitiba: Convênio Itaipu-IPHAN, 1977.

CHMYZ, I. et al. Terceiro relatório das pesquisas realizadas na área de Itaipu (1977-1978). Curitiba: Convênio Itaipu-IPHAN, 1978.

CHMYZ, I. et al. Quarto relatório das pesquisas realizadas na área de Itaipu (1978-1979). Curitiba: Convênio Itaipu-IPHAN, 1979.

CHMYZ, I.; SAUNER, Z. C. Nota prévia sobre as pesquisas arqueológicas no vale do rio Piquiri. Dédalo, Museu de Arqueologia e Etnologia, Universidade de São Paulo, n. 13, p. 7-36, 1971.

CORTElETTI, R. Projeto arqueológico Alto Canoas - PARACA: um estudo da presença Jê no Planalto Catarinense. 2012. Tese (Doutorado em Arqueologia) - Universidade de São Paulo, São Paulo, 2012.

CUNHA, L. P. Índios Xokleng e colonos no Litoral Norte do Rio Grande do Sul (sec. XIX). Porto Alegre: Evangraf, 2012.

ENCICLOPÉDIA DOS MUNICÍPIOS BRASILEIROS, v. XXXII Santa Catarina. Lajes. IBGE, 1959.

HENRY, J. Jungle people. A Kaingang tribe of the Highlands of Brazil. New York: s. ed., 1941.

IBGE, Instituto Brasileiro de Geografia. Brasil. Carta Internacional do Mundo ao Milionésimo. Fundação IBGE - Instituto Brasileiro de Geografia, 1972.

LAVINA, R. Os Xokleng de Santa Catarina: uma etnohistória e sugestões para os arqueólogos. 1994. Dissertação (Mestrado em Estudos Ibero-Americanos) Universidade do Vale do Rio dos Sinos, São Leopoldo, 1994.

MABILDE, Cel. A. P.T. Apontamentos sobre indígenas selvagens da nação "Coroados" que habitam os sertões do Rio Grande do Sul. In: MABILDE, Cel. A. P.T. Anuário do Estado do Rio Grande do Sul, Porto Alegre, ano XIII (1897), p. 145-167 e ano XV (1899), p. 125-151.

MACHADO, N. G. São José do Cerrito, sua gente, sua história. Lages: Papervest Editora, 2004.

MUNSELL COLOR. Munsell Soil Color Charts. Baltimore, Maryland, 1975 edition.

NIMUENDAJU, C. Mapa etno-histórico do Brasil e regiões adjacentes adaptado do Mapa de Curt Nimuendaju 1944. Rio de Janeiro: IBGE, 1981.

SANTOS, S. C. Índios e brancos no Sul do Brasil. A dramática experiência dos Xokleng. Florianópolis: EDME, 1973. 
SCHMITZ, P. I. et al. As tradições ceramistas do planalto sul-brasileiro. Arqueologia do Rio Grande do Sul, Brasil. Documentos 02, São Leopoldo, Instituto Anchietano de Pesquisas, p. 75-130, 1988.

SCHMITZ, P. I. (Coord.). As casas subterrâneas de São José do Cerrito. São Leopoldo: Instituto Anchietano de Pesquisas, 2014.

SCHMITZ, P. I.; ROGGE, J. H. Um sítio da tradição cerâmica Aratu em Apucarana, PR. Revista do Museu de Arqueologia e Etnologia, São Paulo, v. 18, p. 47-68, 2008.

SCHMITZ, P. I.; ROGGE, J. H. Pesquisando a história do Jê Meridional. Pesquisas, Antropologia 70, São Leopoldo, Instituto Anchietano de Pesquisas, p. 7-33, 2013.

SCHMITZ, P. I.; NOVASCO, R. V. Pequena história Jê Meridional através do mapeamento dos sítios datados. Pesquisas, Antropologia 70, São Leopoldo, Instituto Anchietano de Pesquisas, p. 35-41, 2013.

SCHMITZ, P. I. et al. Rincão dos Albinos um grande sítio Jê Meridional. Pesquisas, Antropologia 70, p. 65-131, 2013-a.

SCHMITZ, P. I. et al. Boa Parada um lugar de casas subterrâneas, aterros-plataforma e 'danceiro'. Pesquisas, Antropologia 70, São Leopoldo, Instituto Anchietano de Pesquisas, p. 133-195, 2013-b.

SCHMITZ, P. I. et al. De volta à Boa Parada. um lugar de casas subterrâneas, aterros-plataforma e 'danceiro', Pesquisas, Antropologia 72, 2016.

WIESEMANN, Ú. Os dialetos da língua Kaingang e o Xokleng. Arquivos de Anatomia de Antropologia, Rio de Janeiro III, p. 197-217, 1978. 